\title{
Corrigendum: Uterine artery embolisation as an effective choice for symptomatic fibroids: Five-year outcome
}

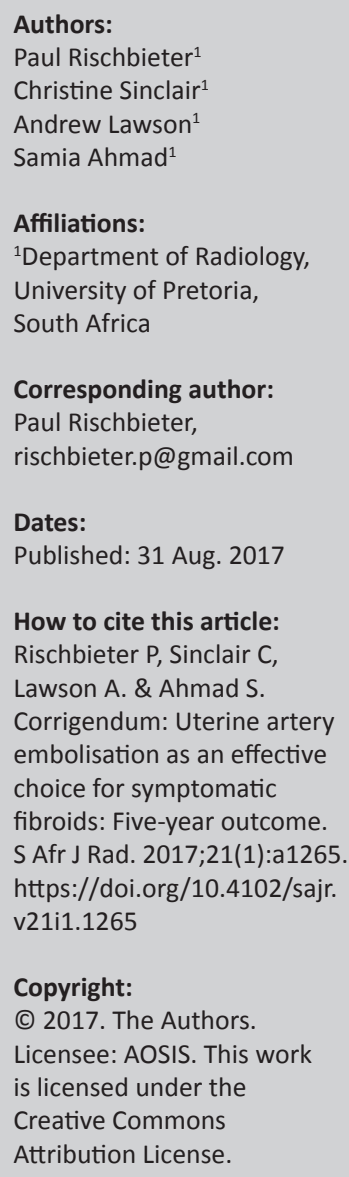

\section{Copyright:}

C) 2017. The Authors. Licensee: AOSIS. This work

is licensed under the

Creative Commons

Attribution License.

In the initially published version of this article, the ethical considerations statement was omitted.

\section{Ethical considerations}

Approval for this study was obtained from the Steve Biko Academic Hospital, the MMed Protocol Committee and the University of Pretoria Faculty of Health Sciences Research Ethics Committee (protocol number 443/2015).

The omission has not altered the study's findings of significance or overall interpretation of the study results. The authors apologise for any inconvenience caused. 